\title{
Postcardiopulmonary Resuscitation Unilateral Flail Chest Unmasked by Dystonia
}

\author{
Swati Umasanker ${ }^{1} \cdot$ Daisy Khera $^{1,2}$ (D) $\cdot$ Siyaram Didel ${ }^{1} \cdot$ Taruna Yadav $^{2}$ \\ Received: 1 April 2021 / Accepted: 3 May 2021 / Published online: 26 May 2021 \\ (C) Dr. K C Chaudhuri Foundation 2021
}

To the Editor: A 4-mo-old infant presented with febrile status epilepticus and required mechanical ventilation for neurogenic stridor and poor Glasgow coma scale of 7 . The child went into cardiac arrest during a repeat episode of seizure while on mechanical ventilation for which he received 6 cycles of highquality CPR (cardiopulmonary resuscitation). Return of spontaneous circulation was established and he was extubated $7 \mathrm{~d}$ later.

The child had episodes of dystonia secondary to the hypoxic insult during initial seizure episodes, which were associated with marked in-drawing of right side of the chest. They disappeared with sleep and increased on agitation. Chest radiograph failed to show any bony or lung parenchymal abnormalities. Possibilities of unilateral diaphragmatic palsy, unilateral bronchial obstruction/bronchomalacia were kept but a bedside ultrasonography failed to demonstrate diaphragmatic palsy and bronchoscopy was not suggestive of bronchial obstruction or bronchomalacia. A contrast enhanced computed tomography (CECT) of the chest showed fracture of the right 2nd to 6th ribs, which was not evident in the chest radiograph. The fractured ribs were attributed to the CPR that the child had received previously and the new onset dystonia had unmasked the flail chest. Chest splinting in the form of prolonged course of noninvasive ventilation along with measures to control pain were given, following which, the child gradually improved.

Children demonstrate a lower susceptibility for chest wall injuries owing to their highly compliant and elastic thoracic cage [1]. CT imaging of the chest has been found to be

Daisy Khera

daisykhera78@gmail.com

1 Department of Pediatrics, All India Institute of Medical Sciences, Jodhpur, Rajasthan, India

2 Department of Diagnostic and Interventional Radiology, All India Institute of Medical Sciences, Jodhpur, Rajasthan 342001, India superior to conventional chest radiography in the detection of such injuries [2].

The possibility of flail chest in any child should be kept when after CPR, severe unilateral or bilateral chest in-drawing is present, even though this is not a common occurrence in children [3]. Conservative management modalities consist mainly of adequate analgesia and chest splinting with either invasive or noninvasive mechanical ventilation [4].

\section{Declarations}

Conflict of Interest None

\section{References}

1. Hashimoto Y, Moriya F, Furumiya J. Forensic aspects of complications resulting from cardiopulmonary resuscitation. Legal Med. 2007;9:94-9.

2. Traub M, Stevenson M, McEvoy S, et al. The use of chest computed tomography versus chest $\mathrm{x}$-ray in patients with major blunt trauma. Injury. 2007;38:43-7.

3. Ondruschka B, Baier C, Siekmeyer M, Buschmann C, Dreßler J, Bernhard M. Cardiopulmonary resuscitation-associated injuries in still-/newborns, infants and toddlers in a German forensic collective. Forensic Sci Int. 2017;279:235-40.

4. Abdallah H, Hosseinian L. Medical management of bilateral flail chest caused by prolonged CPR. Chest. 2019;156:A1886. Available at: https://www.sciencedirect.com/science/article/pii/ S0012369219331277. Accessed on 21 February 2021.

Publisher's Note Springer Nature remains neutral with regard to jurisdictional claims in published maps and institutional affiliations. 